\title{
ELECTROCHEMICAL BEHAVIOR OF MANGANESE DIOXIDE WHEN A PART OF THE COMPOSITE ELECTRODE AND ELECTROCHEMICAL LEACHING OF MANGANESE ORE IN A SULFURIC ACID MEDIUM
}

\author{
A.B. Makhanbetov ${ }^{1}$, B.E. Myrzabekov ${ }^{1,2,}{ }^{凶}$, T.E. Gaipov ${ }^{1}$, A.Tazhibayev ${ }^{1}$ \\ and U.A. Abduvaliyeva ${ }^{2}$ \\ 1 “Alcorlabs" LLP, Almaty, 050010, Republic of Kazakhstan \\ ${ }^{2}$ D.V. Sokolskiy Institute of Fuels, catalysis and electrochemistry, Almaty, 050010, \\ Republic of Kazakhstan \\ Corresponding Author: myrzabekbegzat@mail.ru
}

\begin{abstract}
We investigated the electrochemical behavior of manganese dioxide as a part of a composite electrode of manganese dioxide - graphite $\left(\mathrm{MnO}_{2}+\mathrm{C}\right)$, based on an organic polymer binder. The electrochemical behavior of manganese dioxide $\left(\mathrm{MnO}_{2}\right)$ inside the composite electrode was researched by recording potentiodynamic polarization curves in a sulfuric acid solution. During the cathodic polarization of manganese dioxide in a sulfuric acid medium, a peak reduction of $\mathrm{Mn}^{4+}$ to $\mathrm{Mn}^{2+}$ was observed at a potential of $+1,175 \mathrm{~V}$. The obtained data led to the electrochemical leaching experiments to extract manganese from hardly soluble manganese dioxide. The experiments were carried out at room temperature in an electrolyzer equipped with a mechanical stirrer and the cathode and anode spaces separated by a PVC diaphragm. Lead was used as the cathode material, and graphite electrode was used as the anode. The cathode space was filled with an aqueous solution of sulfuric acid containing particles of manganese dioxide. We investigated the influence of the electrolysis parameters on electrochemical leaching of manganese dioxide and obtained the values of the current yield depending on the cathode current density, the temperature of the medium, the concentration of acid, the mixing intensity and the ratio of liquid to solid (L:S). The obtained data proved the possibility of direct electrochemical leaching of manganese dioxide. The maximum value of $66.8 \%$ current yield was reached at a cathodic current density of $200 \mathrm{~A} / \mathrm{m}^{2}, 50^{\circ} \mathrm{C}$ temperature, and L:S ratio of $6: 1$, mixing speed of $200 \mathrm{rpm}$, with a one-hour duration of the experiment.

Keywords: Manganese, Manganese Dioxide, Composite Electrode, Electrochemical Leaching, Polarization Curves.

RASĀYAN J. Chem., Vol. 14, No.4, 2021
\end{abstract}

\section{INTRODUCTION}

Manganese dioxide $\left(\mathrm{MnO}_{2}\right)$ forms the basis of the highly oxidized manganese ore. Because $\mathrm{MnO}_{2}$ solubility in dilute acidic media is low $^{1}$, the traditional technology of hydrometallurgical processing of manganese oxide ore is based on the ore roasting. The target of the ore roasting process is to maximize the reduction of manganese superoxide to lower oxide ( $\mathrm{MnO})$, which is soluble in sulfuric acid. Gas, oil, and solid fuels are used as reducing agents. ${ }^{2-4}$

Reduced manganese ore (stub) is leached with a solution of sulfuric acid, with the transfer of manganese into the solution.

This traditional technology possesses several flaws:

- the need to use complex equipment to be able to implement the roasting process with the presence of reducing agents;

- carbon-based reducing agents lead to environmental pollution, which decreases the environmental and economic efficiency of this technology.

These drawbacks of the traditional technology triggered the research for more efficient ways to extract manganese from manganese superoxides. It is well known that one of the ways to dilute poorly soluble 
metals and their compounds is to apply electrochemical methods. ${ }^{5-7}$ In this regard, the main goal of this research work was to evaluate the possibility and efficiency of the electrochemical dissolution of manganese dioxide.

Manganese dioxide shows semiconductor properties. To research the electrochemical behavior of manganese dioxide various literature sources ${ }^{8-13}$, suggest using composite electrodes and electrodes with modified $\mathrm{MnO}_{2}$ nanoparticles on the surface of different metals. The other widely used types of electrodes include paste-like electrodes ${ }^{14-16}$, composite electrodes ${ }^{8,17}$, and composite electrodes with thin-film $\mathrm{MnO}_{2}$ modified on the surface of glass-carbon, carbon, graphite, and other types of electrodes. ${ }^{18}$ In the present research, we used a composite electrode produced by curing or pressing a mixture of graphite powder with manganese dioxide and a polymer binder. Polymethylmethacrylate is a binding component. The ratio of manganese dioxide and graphite powder when manufacturing this electrode was 1:1.5, respectively. The advantages of this type of electrode include the simplicity of manufacturing, low solubility of the binding component in both strongly acidic and strongly alkaline media. It is also resistant to temperatures $\left(80^{\circ} \mathrm{C}\right)$ and demonstrates good reproducibility of the results.

This composite electrode made of manganese dioxide-graphite $\left(\mathrm{MnO}_{2}+\mathrm{C}\right)$ was used to record the polarization curves. Anode and cathode behavior of manganese dioxide within the electrode were also researched as a part of this study.

\section{EXPERIMENTAL}

During this research work we used "chemically pure" and "extra pure" chemicals and reagents including sulfuric acid $\left(\mathrm{H}_{2} \mathrm{SO}_{4}\right)$, manganese dioxide $\left(\mathrm{MnO}_{2}\right)$, graphite powder $(\mathrm{C})$, polymethylmethacrylate $\left(\left(\mathrm{C}_{5} \mathrm{O}_{2} \mathrm{H}_{8}\right)_{\mathrm{n}}\right)$, dichloroethane $\mathrm{C}_{2} \mathrm{H}_{4} \mathrm{Cl}_{2}$ and lead and graphite electrodes. All solutions are prepared in distilled water.

\section{Voltammetric Measurements}

We investigated the electrochemical behavior of manganese dioxide and the mechanism of redox reactions in acidic solutions by recording the polarization curves in the potentiodynamic mode with the Autolab PGSTAT potentiostat (Metrohm Autolab, the Netherlands). The measurements were carried out in comparison with the silver-chloride reference electrode in saturated $\mathrm{KCl}$ solution $(\mathrm{E}=+0,225 \mathrm{~V}$, $\left.20^{\circ} \mathrm{C}\right)^{19}$. Platinum wire was used as a counter electrode. Voltammetric measurements were carried out in a thermostatically controlled three-electrode cell. A composite $\mathrm{MnO}_{2}+\mathrm{C}$ electrode with a contact surface area of $0.28 \mathrm{~cm}^{2}$ was used as the main electrode. The polarization curves were recorded at a potential increase rate of $100 \mathrm{mV} / \mathrm{sec}$.

\section{Manufacturing a Composite Electrode From Manganese Dioxide and Graphite $\left(\mathrm{MnO}_{2}+\mathrm{C}\right)$}

To make the electrode we used a powder mixture of manganese dioxide and graphite $\left(\mathrm{MnO}_{2}+\mathrm{C}\right)$ with a component ratio of 1:1.5. Polymethylmethacrylate was dissolved in dichloroethane until a formation of viscous mass, then it was mixed with a composition of manganese dioxide and graphite powder. The obtained paste was placed in a Teflon casing, with a graphite current lead attached to the other side of the casing. The electrode was left to dry for 4 hours. Solvent evaporation and polishing completed the manufacturing process for this solid composite manganese dioxide and graphite $\left(\mathrm{MpO}_{2}+\mathrm{C}\right)$ electrode with a mirror surface and a $6 \mathrm{~mm}$ diameter. The electrode was polished on the polishing paper first, and then we finished polishing with the Teflon tape. Figure-1 shows a schematic representation of the electrode design.

\section{Conducting Electrolysis}

Electrochemical leaching of manganese ore was carried out in a stationary electrolysis mode when metal plates with high current conductivity can be used as cathodes. In our case, we used a lead electrode as the cathode. Its high ductility makes it suitable for any design. The release of hydrogen on a lead electrode is accompanied with a significant overvoltage, which expands the scope of applying this metal as a cathode. Therefore, we investigated the parameters of electrolysis during the process of electrochemical leaching using a lead cathode. A graphite electrode was used as the anode. 
RASĀYAN J. Chem.

Vol. 14 | No. 4 |2202-2208| October- December | 2021

Electrochemical leaching of manganese dioxide was carried out in a cylindrical cell. This electrolyzer has no corners and the electrodes are located over the entire area at equal distances. The cathode and the anode are separated by a diaphragm. A PVC fabric is used as a diaphragm material. Figure-2 demonstrates the design of the electrolyzer.

When the electrolyte solution is mechanically stirred, the ore particles only come into contact with the cathode surface.

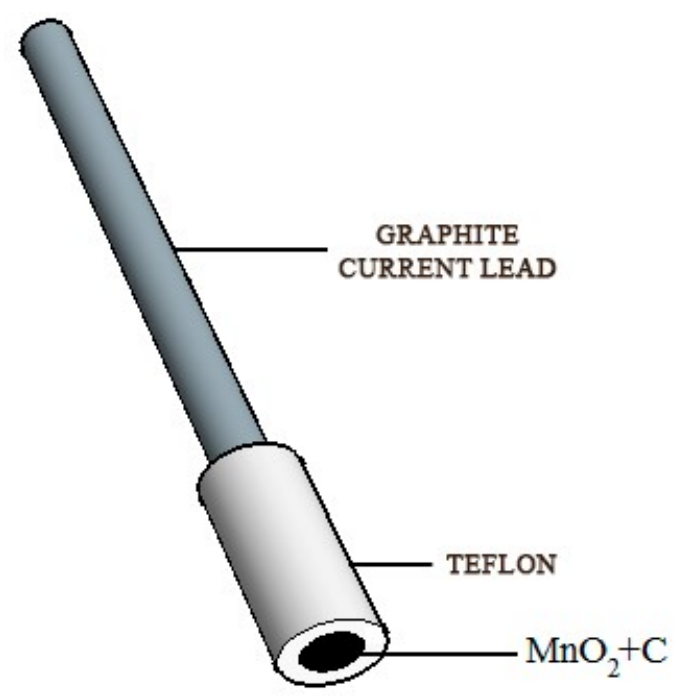

Fig.-1: Composite $\mathrm{MnO}_{2}+\mathrm{C}$ Electrode
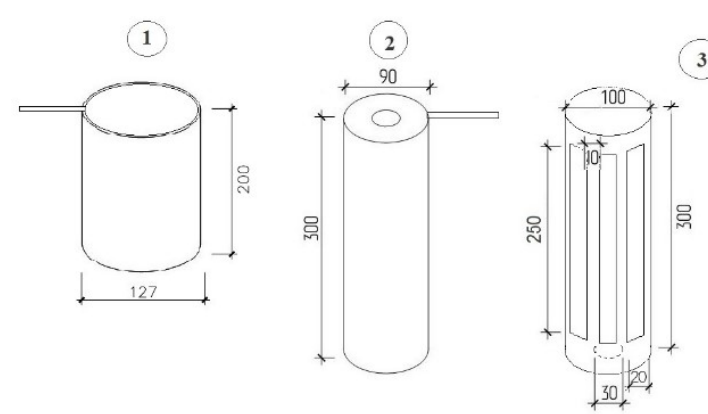

3
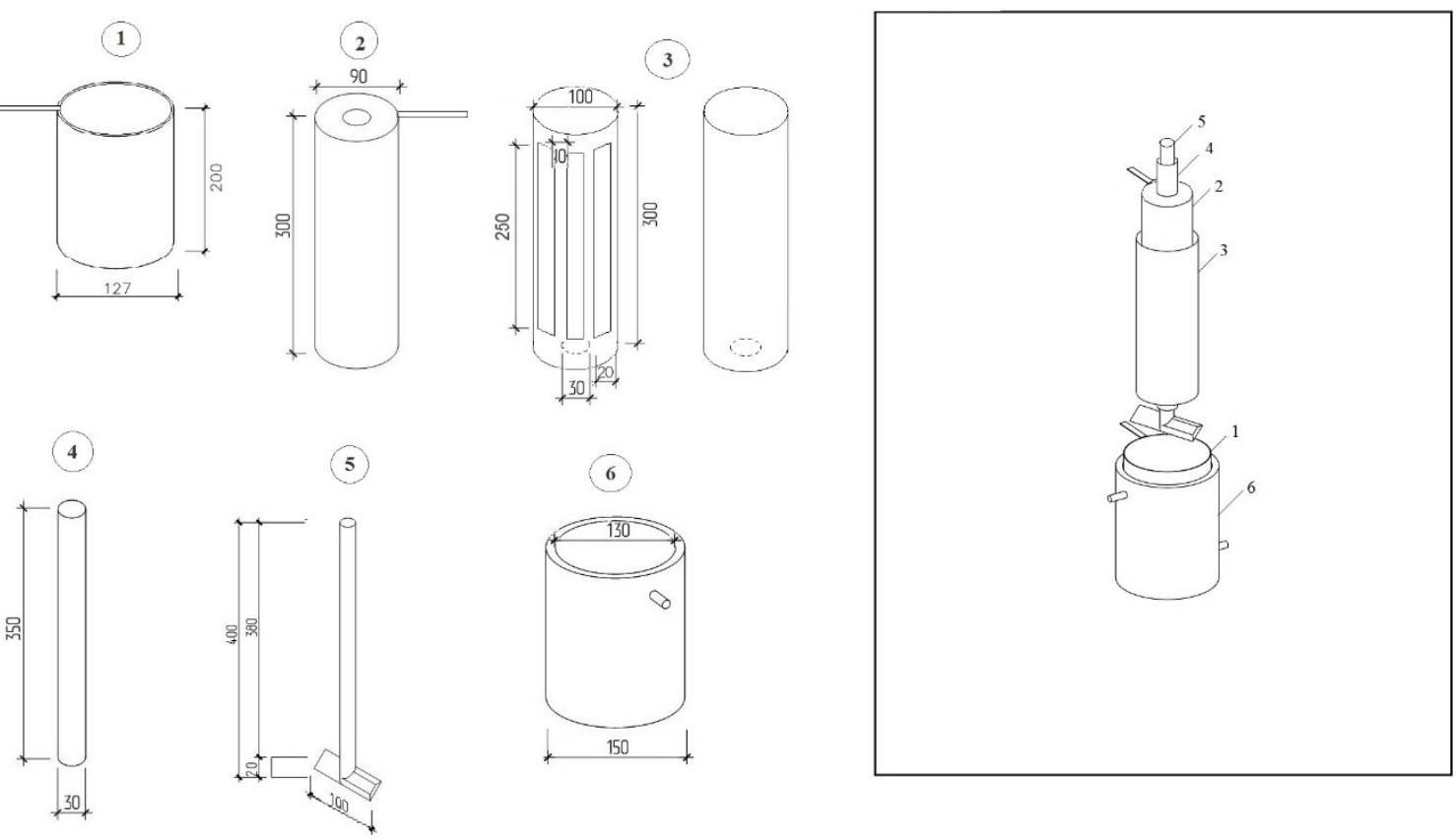

1 - the cathode; 2 - the anode; 3 - the diaphragm; 4 - the tube;

5 - the stirrer; 6 - the thermostated tank

Fig.-2: Diagram of the Electrolyzer and its Components

$\mathrm{MnO}_{2}$ particles with the catolite are placed into the space between the cathode and the diaphragm. During mechanical stirring, the $\mathrm{MnO}_{2}$ contained in the catholyte comes into contact with the cathode surface. The 
RASĀYAN J. Chem.

Vol. 14 | No. 4 |2202-2208| October- December | 2021

diaphragm protects the $\mathrm{MnO}_{2}$ particles from coming into contact with the anode. $\mathrm{MnO}_{2}$ particles exhibit electrochemical activity when they collide and come into direct contact with the cathode. Therefore, $\mathrm{MnO}_{2}$ is reduced and transferred into the solution during the cathodic polarization, as the reaction (1) shows.

\section{RESULTS AND DISCUSSION}

As the result of the investigation of the electrochemical behavior of manganese dioxide in the composite electrode $\mathrm{MnO}_{2}+\mathrm{C}$, cathode polarization curves were recorded. Figure 3 shows the cathodic potentiodynamic polarization curve of $\mathrm{MnO}_{2}+\mathrm{C}$ reduction in an aqueous solution of sulfuric acid with a concentration of $100 \mathrm{~g} / \mathrm{l}$. It was proven that the two-electron reduction of manganese oxide with the formation of manganese (II) ions happens at a stationary potential of $+1,175 \mathrm{~V}$ by the following reaction (1):

$$
\mathrm{MnO}_{2}+4 \mathrm{H}^{+}+2 \mathrm{e}^{-} \rightarrow \mathrm{Mn}^{2+}+2 \mathrm{H}_{2} \mathrm{O} \quad \mathrm{E}^{\mathrm{o}}=+1,228
$$

Starting with a potential of $-0,775 \mathrm{~V}$, the reduction of hydrogen ions proceeds according to the following reaction (2):

$$
2 \mathrm{H}_{2} \mathrm{O} \rightarrow \mathrm{H}_{2}+2 \mathrm{OH}^{-}
$$

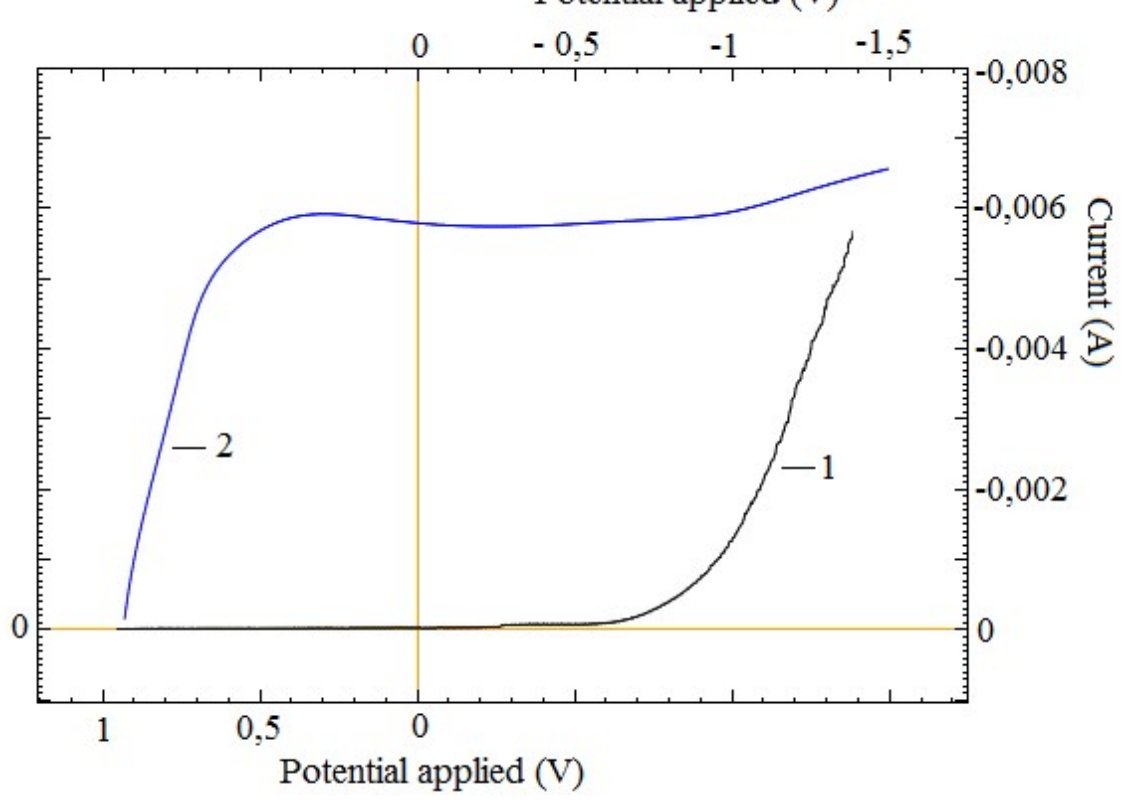

$$
\begin{gathered}
\mathrm{V}=100 \mathrm{mV} / \mathrm{s},\left[\mathrm{H}_{2} \mathrm{SO}_{4},\right]=100 \mathrm{~g} / 1, \mathrm{t}=20^{\circ} \mathrm{C} \\
\text { 1- glass-graphite electrode; } 2-\mathrm{MnO}_{2}+\mathrm{C} \text { electrode } \\
\text { Fig.-3: Cathodic Potentiodynamic Polarization Curves }
\end{gathered}
$$

Visually, the formation of gas bubbles was observed. Along with the formation of hydrogen ions on the surface of the observed electrode at the above-mentioned potential, the process of cathodic reduction of manganese (II) ions also proceeds according to the following reaction (3):

$$
\mathrm{Mn}^{2+}+2 \mathrm{e}^{-} \rightarrow \mathrm{Mn}^{0} \quad \mathrm{E}^{\mathrm{o}}=-1,179
$$

The polarization curve on a glass graphite electrode in a sulfuric acid medium with a concentration of 100 $\mathrm{g} / \mathrm{l}$ was also recorded to verify the reliability of the results. As one can observe from the resulting curve (Figure 3), only the reduction current of hydrogen ions was recorded starting from the potential of $-0,375$ V. Thus, it was confirmed that the manganese dioxide as a part of the composite electrode exhibits high electrochemical activity in a sulfuric acid medium.

Figure 4 shows the cathode-anode potentiodynamic polarization curve $\mathrm{MnO}_{2}+\mathrm{C}$ recorded in an aqueous solution of sulfuric acid with a concentration of $100 \mathrm{~g} / 1$. The processes illustrated by Figure 3 were 2205 
RASĀYAN J. Chem.

Vol. 14 | No. 4 |2202-2208| October-December | 2021

observed in the cathode space. When the potential shifts from the cathode space to the anode space at a potential of $-0,775 \mathrm{~V}$, the reverse oxidation of metal manganese occurs on the electrode surface.

Oxidation of elementary manganese to manganese (II) ions proceeds by the following reaction (4):

$$
\mathrm{Mn}^{0}-2 \mathrm{e}^{-} \rightarrow \mathrm{Mn}^{2+} \quad \mathrm{E}^{\mathrm{o}}=-1,179
$$

Figure-4 shows that the following chemical reactions proceed in the solution with a positive potential shift: starting from a potential of $+1,175 \mathrm{~V}$ the formation of oxygen by reaction (5), starting from a potential of $+1,825 \mathrm{~V}$ the oxidation of manganese dioxide to permanganate ions by reaction (6).

$$
\begin{array}{ll}
2 \mathrm{H}_{2} \mathrm{O}-4 \mathrm{e}^{-} \rightarrow \mathrm{O}_{2}+4 \mathrm{H}^{+} & \mathrm{E}^{\mathrm{o}}=+1,229 \\
\mathrm{MnO}_{2}+2 \mathrm{H}_{2} \mathrm{O}-3 \mathrm{e}^{-} \rightarrow \mathrm{MnO}_{4}^{-}+4 \mathrm{H}^{+} & \mathrm{E}^{\mathrm{o}}=+1,692
\end{array}
$$

It should be noted, that the solution in the near-electrode space turns into purple-pink color.

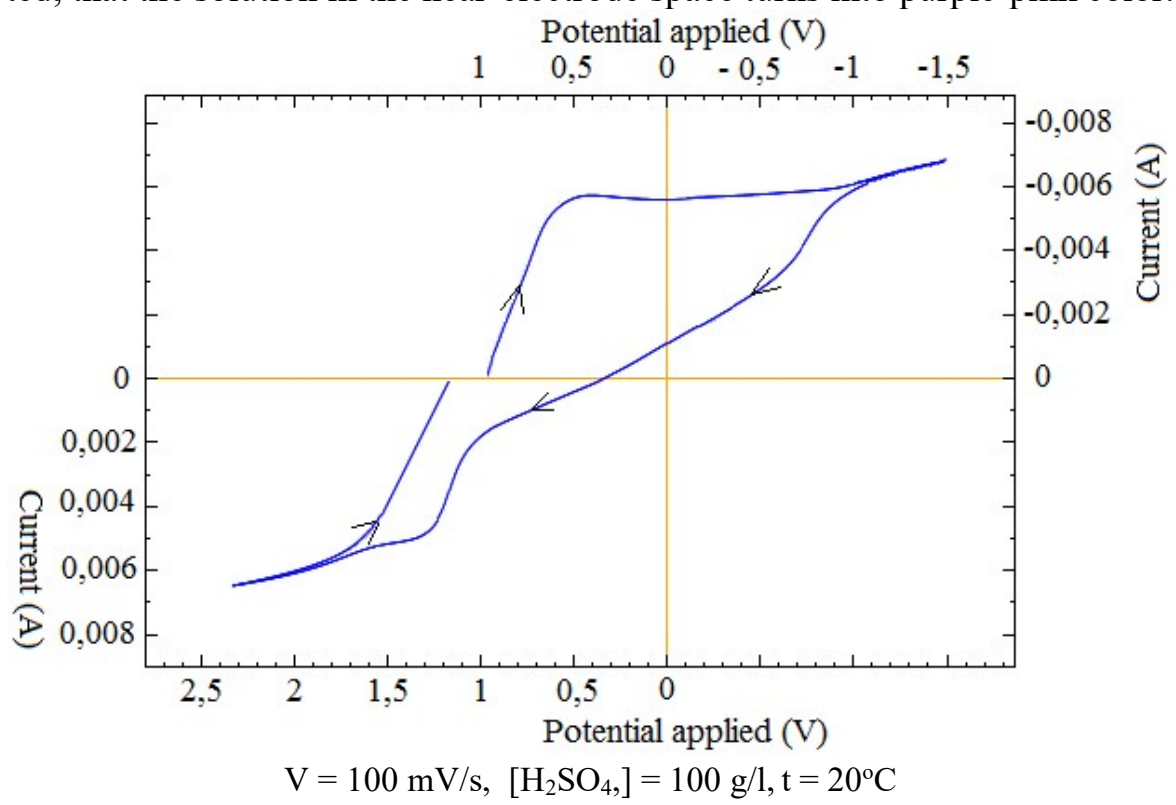

Fig.-4: Cyclic Cathode-anode Potentiodynamic Polarization Curve recorded on the $\mathrm{MnO}_{2}+\mathrm{C}$ Electrode

The results of this research prove that during cathodic polarization it is possible to reduce manganese dioxide to manganese (II) ions in a solution of sulfuric acid. The cathodic reduction of manganese dioxide and the conversion of manganese into solution served as the basis for research on electrochemical leaching.

The influence of the electrolysis parameters on the current yield of the manganese dissolution during electrochemical leaching of manganese ore was researched. In the course of this research, the dependences of the current yield of the manganese dissolution on the cathode current density, the concentration of sulfuric acid, the mixing rate, the medium temperature, and the L:S ratio were determined.

With an increase in cathode current density in the range of $200-800 \mathrm{~A} / \mathrm{m}^{2}$, the current yield of manganese dissolution decreases from $22 \%$ to $3 \%$ respectively. This is because with an increase in cathode current density, the discharge of hydrogen ions increases, which leads to excessive current consumption and decreases the efficiency of the main process.

The effect of the acid concentration on the current yield of the dissolution of manganese was also investigated. Increasing the acid concentration within the electrolyte from $50 \mathrm{~g} / 1$ to $100 \mathrm{~g} / 1$ leads to an increase in current yield from $20.9 \%$ to $22.2 \%$ respectively. A further increase in the acid concentration to 
$200 \mathrm{~g} / 1$ leads to a decrease in the current yield down to $16.8 \%$. This is because a high concentration of acid increases the overvoltage of hydrogen release at the cathode and as a result, the current yield of manganese dissolution decreases.

As we mentioned above, manganese dioxide has low electrical conductivity and is poorly soluble in water. Its reduction can take place only on the surface in contact with the cathode. Therefore, in our case, mixing was an external force that allowed the ore to come into contact with the cathode's surface. Leaching was carried out at stirring rates of $200 \mathrm{rpm}, 400 \mathrm{rpm}$, and $600 \mathrm{rpm}$. The results of the experiments can be found in Table-1.

Table-1: The Effects of Electrolysis Parameters on the Current Yield of Manganese Dissolution

\begin{tabular}{|c|c|c|c|}
\hline No. & Electrolysis Parameters & Value & Current Yield, \% \\
\hline \multirow{3}{*}{1} & \multirow{3}{*}{$\begin{array}{l}\text { Current Density on Cathode, } \\
\qquad \mathrm{A} / \mathrm{m}^{2}\end{array}$} & 200 & 22.2 \\
\hline & & 300 & 10.9 \\
\hline & & 500 & 3 \\
\hline \multirow{3}{*}{2} & \multirow{3}{*}{ Acid Concentration, g/l } & 50 & 20.9 \\
\hline & & 100 & 22.2 \\
\hline & & 150 & 16.8 \\
\hline \multirow{3}{*}{3} & \multirow{3}{*}{ Mixing Rate, rpm } & 200 & 32 \\
\hline & & 400 & 28 \\
\hline & & 600 & 22.2 \\
\hline \multirow{3}{*}{4} & \multirow{3}{*}{ Electrolyte Temperature, ${ }^{\circ} \mathrm{C}$} & 25 & 32 \\
\hline & & 50 & 41.8 \\
\hline & & 75 & 37.9 \\
\hline \multirow{3}{*}{5} & \multirow{3}{*}{ L:S Ratio } & $6: 1$ & 66.8 \\
\hline & & $8: 1$ & 43.9 \\
\hline & & $10: 1$ & 41.8 \\
\hline
\end{tabular}

The influence of the electrolyte temperature on the process of electrochemical leaching of manganese was analyzed. The experiments were carried out at temperatures of $25^{\circ} \mathrm{C}, 50^{\circ} \mathrm{C}$, and $75{ }^{\circ} \mathrm{C}$. With an increase in the temperature of the electrolyte from $25{ }^{\circ} \mathrm{C}$ to $50{ }^{\circ} \mathrm{C}$, the current yield increased from $32 \%$ to $41.8 \%$. The higher the temperature, the higher the rate of reduction of higher manganese oxides to lower oxide $(\mathrm{MnO})$ with its further dissolution. However, when the temperature increased to $75{ }^{\circ} \mathrm{C}$, the current yield value went down to $37.9 \%$. This is due to an increase in the proportion of the (2) reaction.

The L:S ratios of $6: 1,8: 1$ and 10:1 were examined. Table 1 shows that with an increase in L:S ratio, the current yield of manganese dissolution decreases. This is because the increasing L:S ratio leads to fewer opportunities for the ore to come into contact with the cathode. The maximum current yield was observed at $\mathrm{L}: \mathrm{S}$ ratio of $6: 1$.

Thus, the optimal values of the electrolysis parameters are: the cathode current density of $200 \mathrm{~A} / \mathrm{m}^{2}$, the temperature of $50{ }^{\circ} \mathrm{C}$, the L:S ratio of $6: 1$, mixing intensity of $200 \mathrm{rpm}$ and duration of electrolysis of 1 hour. The maximum value of the current yield is $66.8 \%$.

\section{CONCLUSION}

The obtained results allow us to conclude that a composite manganese dioxide - graphite $\left(\mathrm{MnO}_{2}+\mathrm{C}\right)$ electrode proposed in this work shows good electrochemical activity in a sulfuric acid solution, which makes it possible to reduce the manganese dioxide from the electrode composition to manganese (II) ions using cathodic polarization. This process could serve as a primary stage of the high-purity cathode manganese production. During the anodic polarization of the composite electrode, manganese dioxide $\left(\mathrm{MnO}_{2}\right)$ is oxidized to permanganate ions $\left(\mathrm{MnO}_{4}-\right)$, which leads to the solution changing color to purplepink.

During electrochemical leaching, two processes occur simultaneously: reduction of higher manganese oxides and the transition of manganese to an aqueous solution from the reduced ore. Thus, it is possible to eliminate the traditional process of ore roasting from hydrometallurgical processing technology, which should allow the extraction of manganese from the ore with greater efficiency and lower operating costs. 
RASĀYAN J. Chem.

Vol. 14 | No. 4 |2202-2208| October- December | 2021

This solution has the potential to increase the environmental and economic efficiency of traditional technological processes.

\section{ACKNOWLEDGEMENT}

The work was conducted under research grant project of AP08052565 "Development of the technology for producing metal manganese from manganese ores by electrochemical leaching". The authors would like to place on record their sincere gratitude to the Ministry of Science and Education of the Republic of Kazakhstan for financial support.

\section{REFERENCES}

1. M. Harris, D.M. Meyer, K. Auerswald, Journal of the South African Institute of Mining and Metallurgy, 77(7), 137(1977), http://doi.org/10.10520/AJA0038223X 738

2. A.B. Makhanbetov, A. Zharmenov, A. Bayeshov, B. Mishra, O. Baigenzhenov, Russian Journal of Non-Ferrous Metals, 54(6), 606(2015), http://doi.org/10.3103/S1067821215060061

3. A.S. Kolesnikov, I.V. Sergeeva, N.E. Botabaev, A.Zh. Alzhanova, Kh.A. Ashirbaev, Izvestiya. Ferrous Metallurgy, 60, 759(2017), http://doi.org/10.17073/0368-0797-2017-9-759-765

4. A.S. Kolesnikov, I.V. Sergeeva, N.E. Botabaev, A.Zh. Alzhanova, Kh.A. Ashirbaev, Steel in Translation, 47, 605(2017), http://doi.org/10.3103/S0967091217090078

5. B.E. Myrzabekov, A.B. Bayeshov, A.B. Makhanbetov, B. Mishra, and O.S. Baigenzhenov, Metallurgical and materials transactions B, 49(1), 23(2018), http://doi.org/10.1007/s11663-017$\underline{1139-\mathrm{x}}$

6. T.E. Gaipov, A. Bayeshov, B.E. Myrzabekov, E.K. Abdulina, News of the National Academy of Sciences of the Republic of Kazakhstan, Series of Geology and Technical Sciences, 3(441), 196(2020), http://doi.org/10.32014/2020.2518-170 X.73

7. A.S. Kolesnikov, V.N. Naraev, M.I. Natorhin, A.A. Saipov, O.G. Kolesnikova, Rasayan Journal of Chemistry, 13, 2420(2020), http://doi.org/10.31788/RJC.2020.1346102

8. E.C. Rios, A.V. Rosario, R.M.Q. Mello, L. Micaroni, Journal of Power Sources, 163, 1137(2007), http://doi.org/10.1016/j.jpowsour.2006.09.056

9. H. Beyenal, J.T. Babauta, Published by John Wiley \& Sons, 167(2015).

10. D.M. Aronbaev, S.D. Aronbaev, G.Z. Narmaeva, D. Isakova, Avicenna, 41, 4(2019).

11. D. Aronbaev, S. Aronbaev, G. Narmaeva, D. Isakova, Austrian Journal of Technical and Natural Sciences, 1(2), 40(2020), http://doi.org/10.29013/AJT-20-1.2-40-46

12. V. Subramanian, H.W. Zhu, B.Q. Wei, Journal of Power Sources, 159, 361(2006), http://doi.org/10.1016/j.jpowsour.2006.04.012

13. B.M. Zakaria, D. Leszczynska, Chemosensors, 7(1), 2(2019), http://doi.org/10.3390/chemosensors7010001

14. Y.H. Bai, Y. Du, J.J. Xu, H.Y. Chen, Electrochem Communications, 9(10), 2611(2007).

15. E. Mehmeti, D.M. Stankovic, S. Chaiyo, L. Svorc, K. Kalcher, Microchim Acta,183, 1619(2016). http://doi.org/10.1007/s00604-016-1789-4

16. C.E. Langley, B. Çljukic, C.E. Banks, G.R. Compton, Analytical sciences, 23, 165(2007), http://doi.org/10.2116/analsci.23.165

17. Z. Taba, J. Wang, Electroanalysis, 3, 215(1991), http://doi.org/10.1002/elan.1140030313

18. D.G. Gromadsky, Electronic Processing of Materials, 52(3), 58(2016).

19. A.M. Sukhotina, Handbook of Electrochemistry, Chemistry, Leningrad, p.44-44(1981).

[RJC-6491/2021] 